\title{
Wider representation
}

Sir, I am writing in response to Rizwana Lala and Wendy Thompson who raised important issues of equality, diversity and inclusion in their opinion piece 'An equal world is an enabled world: equality in the dental profession. ${ }^{1}$

While I agree it is important that women feel encouraged and enabled to develop as leaders in the profession, I feel it is pertinent to point out that there are presently a number of effective female dental leaders in the UK.

Within the BDA's wider committee structures, the UK Council, three of the four Country Council representative committees - the England Community Dental Services Committee, the Young Dentist Committee and Scottish Hospitals Dental Reference group - are all chaired by women. The present and immediate past president of the $\mathrm{BDA}$ are female, as is the current chair of the LDC. Outside the representative arena, two of the four UK CDO's are female, and the speaker of the World Dental Federation is also a woman who hails from these shores. Many females in the profession run successful practices, lead dental and medical teams in Trusts and take senior roles in regulatory, indemnity, academic and NHS organisations.

As a founder member of Women in Dentistry way back in the 1980s, I am all too aware of the conscious and unconscious bias women can suffer in the professional workspace. We must not be complacent, and indeed the present makeup of the elected Board of the BDA is certainly not representative of the gender demographics of the profession. I am pleased the BDA is taking this issue seriously in their strategic deliberations, and the authors will have hopefully engaged with the governance review survey to make their voices heard.

Female dentists in the UK have achieved leadership roles by their own merit and hard work, and we must ensure they are highlighted and rightly celebrated.

R. McMullan, President, BDA

\section{Reference}

1. Lala R and Thompson W. 'An equal world is an enabled world': Equality in the dental profession. BDJ In Pract 2020; 33: 17-19.

\section{ADG and BDA: pull the plug on ortho tendering}

The BDA and Association of Dental Groups (ADG) have urged NHS England to suspend all active procurement for orthodontic services.

The two groups have expressed no confidence in the tendering exercises, following the chaotic collapse of the process covering NHS orthodontics in the Midlands and East, stating that any continuation will jeopardise patient care and the stability of the service.

The process to decide on decade-long contracts, worth over $£ 65$ million, was suspended in December after six chaotic months dogged by administrative failings that had forced the reopening of tenders. The national process has prompted multiple legal challenges and, in the North, at least six separate legal actions.

In an open letter to NHS England, both Associations have relayed their members' serious concerns on procurement. In sharp focus has been failures on consistency, transparency and equal treatment in relation to marking of bids, where the standards fell far below the requirements of law and good procurement practice.

While NHS England has pledged a 'lessons learned' exercise, the ADG and BDA have demanded that procurements - where contracts have not yet been awarded and entered into - must continue to be suspended so that the flaws of these processes can be included within the scope of any review.

The BDA and ADG have previously called on Health and Social Care Secretary Matt Hancock to halt all future procurements and to outline plans to compensate individual providers who have been left up to $£ 30,000$ out of pocket. 